\title{
Are We Still Missing the Target in Trying to Prevent and Treat Human Cancers?
}

\author{
James E. Trosko* \\ Department of Pediatrics/Human Development, USA
}

\section{ISSN: 2637-773X}

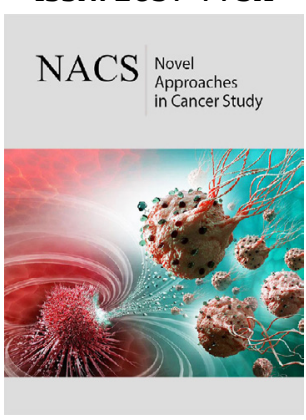

*Corresponding author: James E Trosko, Department of Pediatrics/Human Development, East Lansing, Michigan 48824, USA

Submission: 慍 July 12, 2019

Published: 啙August 26, 2019

Volume 3 - Issue2

How to cite this article: James E Trosko. Are we Still Missing the Target in Trying to Prevent and Treat Human Cancers?. Nov Appro in Can Study. 3(2) NACS.000556.2019.

DOI: 10.31031/NACS.2019.03.000556

Copyright@ James E Trosko, This article is distributed under the terms of the Creative Commons Attribution 4.0 International License, which permits unrestricted use and redistribution provided that the original author and source are credited.

\begin{abstract}
Solving the problem of preventing or treating cancers is still a major problem. While much is known about those multi-disciplinary contributors to the initiation, promotion and progression phases of human cancers, major hurdles to efficacious prevention and treatment involve, while recognizing that there are many known factors that can influence human carcinogenesis, little integration of this knowledge has been used. This brief "Opinion" paper hypothesizes that, by recognizing the multi-stage, multi-mechanism process of carcinogenesis, the roles of organ-specific adult stem cells as the "targets for two types of "cancer stem cells", and new strategies for nutritional / dietary intervention, could help in the prevention of early susceptibility for cancers later in life, as well as for treatment for the two very different "cancer stem cells".
\end{abstract}

Keywords: Stem cell hypothesis of cancer; Human adult stem cells; Cancer stem cells; Multi-stage; Multi-mechanism hypothesis of carcinogenesis

"In this light, a new perspective for therapeutic intervention by directing differentiation and restoring communications between cancer cells is certainly relevant, and the example of gap junctions is illuminating" [1].

\section{Introduction}

Is searching for a "Rose in a Dung Heap" the correct strategy for future cancer research? Starting from the view point that there are two philosophical approaches to solve the extremely complex problem of preventing and treating cancers, namely (a) the empirical, unbiased approach of collecting large amount of observations in hopes of finding a pattern (i.e., current use of data mining or computational biology and "Artificial Intelligence ") or (b) a specific hypothesis-mechanistically based, deductive approach), it seems, while both approaches are being used, we still have made no "conceptual" breakthrough. In spite everyone today recognizing that this cancer problem requires a true multi-disciplinary approach, it still must be based on some biological facts. With all the known facts about many physical (radiations), chemical (natural toxins/synthetic toxicants) and biologics (viruses, bacteria, fungi) having some influence on human carcinogenesis, the link to these factors is only somewhat known to be involved in the multi-stage/multi-mechanism of human carcinogenesis $[2,3]$. Yet, the integration of the psychological, social, anthropological, cultural, economic, political and ecological sciences has only been weakly linked to the evolutionary and biological sciences [4-7]. As this article is grounded in my limited 50 years of experience in but a few disciplines, as an "opinion" writer, I feel, while the multidisciplinary field of carcinogenesis is still very incomplete, there is sufficient solid scientific information that could supply a new direction. First, we know that there are genetic, racial, developmental, gender, environmental, dietary, nutritional, immunological, behavioral, ecological, cultural, and economic/political factors that influence the cancer process. In addition, we know that cancers have their origin in a single cell $[8,9]$. Today, there is a substantial evidence that the organ-specific adult stem cell and its early progenitor daughter are the target cells to become, in time, a "cancer stem cell" [10-12]. It is now thought that these "cancer stem cells" ought to be the target for both prevention and therapy $[13,14]$. Moreover, there is ample evidence of the power of nutrition and diets to influence, either positively or negatively, the frequency of many cancers, especially with the observations of caloric restricted, excess calories, and changes in diets due to diaspora of both peoples and foods, especially in large populations during the Second War in Europe and Japan $[15,16]$. This is now leading some investigators to view that pregnant women, exposed 
to many toxins/toxicants/behaviors, diets, can influence diseases later in life (The "Barker hypothesis" [17]).

\section{Understanding the Role of Adult Stem Cells in the Multi-Stage, Multi-Mechanism Process of Human Carcinogenesis}

Putting this vague overview into sharper vision, we now have to look at recent advances in the isolation of human stem cells ( embryonic; "induced pluripotent" or "iPS", somatic nuclear transfer, and organ-specific adult stem cells) in the context of the multistage, multi-mechanism process of human carcinogenesis [18], the "stem cell hypothesis"[19-26] of cancer and "cancer stem cells". If we assume the single cell of any organ is the first cell that is altered to become the "cancer stem cell", then the question becomes, "What is that cell?". Is it an adult stem cell that is blocked from terminally differentiation ("Oncogeny as partially blocked ontogeny" [20]); or Is it a somatic differentiated cell that is re-programmed to become "embryonic -like" in an adult tissue? [21]. In this short "opinion" paper, a strong argument can be made that there is sufficient evidence that the adult-organ-specific stem cell is the target cell for this "initiation" event to occur, as in the case of blood cancers; breast cancers, prostate cancers neural-derived cancers, intestinal cancers and skin cancers.

However, when this "initiation" event in a single organ-specific stem cell occurs, this is not a full-blown cancer. In fact, each human being has many organ-specific adults "initiated" stem cells. What is needed, in order that all the "hallmarks of cancer" $[27,28]$ are acquired, is to allow these single cells to remain "immortal" or undifferentiated in order to be stimulated to proliferate to accrue more mutations and other epigenetic alterations and not to die by apoptosis or autophagy. This process is referred to as the promotion process, which can stimulate proliferation of this single "initiated" stem cells by agents or conditions that are "epigenetic" in nature, such as growth factors, hormones, cytokines, dietary factors, medications, non-toxic natural and synthetic chemicals, microbial toxins, wounding, non-mutagenic cytotoxins/cytotoxicants) [29]. After the expansion of these "initiated" cells by these non-mutagenic "promoters", there can be the appearance of benign lesions (nodules in the breast; polyps in the colon, papillomas in the skin, lesions in the liver), after systemic exposures at threshold levels and in the absence of "anti-promoters" [30]. However, after this expansion of initiate stem cells, finally, one cell acquires all the genotypic/ phenotypic changes required to invade and to metastasize into a malignant cancers. At this stage, as noted by current studies, the tumor is very heterogeneous [31].

However, while pathologists have long recognized for many tumors, there are two generalized classes: one being very "embryonic- like", while the other being partially differentiated -like. The basal carcinomas and squamous carcinomas of the skin; the estrogen receptor positive versus the triple negative receptor beast carcinomas; the "flat-type" versus polyp -type colon carcinomas; etc. Other classifications include oncogene-associated and non-oncogene -associated cancers. It is here that, I propose that there exists in these tumors two types of "cancer stem cells" [32]. The colon cancer cells provide a great example [33], which I suggest existing in all organ tumors. The lining of the colon has few cancer stems cells in the ascending, transverse and descending sections. The tumors that do appear were, in all probability, derived and initiated from the adult colon stem cells. However, what is seen is that the polyp-type are partially differentiated and treatable. The "flat-type" colon tumors, to date, have not been treatable. Both types were probably "promoted" by different kinds of "promoters". Since, the microbiome has been implicated in many diseases, including cancer and the different regions of the colon contain different microbiome population, it might be that the promoters might be the different toxins of these different bacteria that might cause stimulation of very early differentiation of the colon stem cell (polyp -type) and the undifferentiated colon stem cell that has been initiated is now promoter by other bacterial toxins to form the "flattype" of colon tumor.

If this hypothesis is true, cancer therapy must never use the same strategy that might work sometimes on the same "type" of cancer, but rather be designed to target either the "cancer stem cell"- type that is undifferentiated or "stem -like", namely expressing the Oct4A gene [22] and not express any connexin gene , a gene expression required for differentiation [34]. The more differentiated-type of cancer is not expressing the 0ct4A gene but is expressing the connexin or gap junction genes. Therefore, treatment of the undifferentiated type must use therapies that can induce the Oct4A gene to be transcriptional repressed and the connexin gene be expressed. On the other hand, the partially differentiated cells should restore functional gap junctional intercellular communication to either die by apoptosis or to terminally differentiate. In all tumors that are heterogenous with both cancer stem cells and non-cancer stem cells, the first objective is to remove most of the "cancer non-stem cells, in order to target the few "two-types of "cancer stem cells". These are still tall orders but, without taking into account these two types of "cancer stem cells", progress will be delayed.

\section{Conclusion}

It has been proposed that there exist two types of "cancer stem cells", one derived from the undifferentiated adult organspecific stem cell, while the other has been derived from a very early differentiated adult organ specific stem cell. The former's phenotype is one characterized by being very embryonic-like, with the expression of the Oct4A gene and the lack of expression of the connexin genes. These cells have no functional gap junctional intercellular communication. The latter "cancer stem cells" would be "partially differentiated", having no Oct4A expression but expressing some connexin gene. Since all cancer stem cells are derived from normal organ specific stem cells, to prevent cancers, one, could, in principle, try to prevent expansion of adult organspecific stem cells during in utero development. Once these adult organ-stem cells are initiated in the adult, chemoprevention of agents that could block organ-specific natural or synthetic tumor promoters acting on these initiated cells by dietary intervention. 
In the case of cancer therapy, in both cases, these two types of "cancer stem cells" have no functional gap junctional intercellular communication. The objective for cancer therapy is to transcriptionally suppress the Oct4A gene but transcriptionally induce the connexin gene in the former type. In the case of the latter type, since these cells already have suppressed the Oct4A gene and expressed the connexin gene but their connexin proteins have been rendered non-functional by some oncogene, the objective is to get the expressed connexin message/protein to become functional.

\section{Acknowledgment}

I wish to acknowledge all my undergraduate, graduate students, medical \& veterinary students, postdoctoral fellows, Visiting Scholars, and Colleagues, \& Collaborators who have influenced my thinking by their hard work.

\section{References}

1. Capp JP (2005) Stochastic gene expression, disruption of tissue averaging effects and cancer as a disease of development. Bioessays 27(12): 1227-1285.

2. Weinstein IB, Gattoni CS, Kirschmeier P, Lambert M, Hsiao W, et al (1984) Multistage carcinogenesis involves multiple genes and multiple mechanisms. J Cell Physiol 3: 127-137.

3. Pitot HC, Dragan YP (1991) Facts and theories concerning the mechanisms of carcinogenesis. FASEB J 5(9): 2280-2286.

4. Potter VR (1971) Bioethics: bridge to the future. Prentice-Hall, New York, USA.

5. Lacina L, Coma M, Dvovankosa B, Kodet O, Melegová N, et al. (2019) Evolution of cancer progression in the context of darwinism. Anticancer Res 39(1): 1-16.

6. Trosko JE (2015) Global bioethical prevention of the collision of biological and cultural evolution on miserable human survival. Sociology Study 5(4): 295-313.

7. Carruba G, Trosko JE (2017) The long evolutionary journey of cancer from ancestor to modern humans' critical reviews in oncogenesis 22(34): 323-352.

8. Pierce GB (1974) Neoplasms, differentiation and mutations. Am J Pathol 77(1): 103-118.

9. Fialkow PJ (1976) Clonal origin of human tumors. Biochim Biophys Acta 458(3): 283-321.

10. Bonnet D, Dick JE (1997) Human acute myeloid leukemia is organized as a hierarchy that originates from a primitive hematopoietic cell. Nat Med 3(7): 730-737.

11. Reya T, Morrison SJ, Clarke MF, Weissman IL (2001) Stem cells, cancer, and cancer stem cells. Nature 414(6859): 105-111.

12. Al-Hajj M, Wicha MS, Benito-Hernandez,A, Morrison SJ, Clarke MF (2003) Prospective isolation of tumorigenic breast cancer cells. Proc Natl Acad Sci USA 100(7): 3983-3988.

13. Yoshida GJ, Saya H (2016) Therapeutic strategies targeting cancer stem cells. Cancer Sci 107(1): 5-11.

14. Ning X, Shu J, Du Y, Ben Q Li Z (2013) Therapeutic strategies targeting cancer stem cells. Cancer Biol Ther 14(4): 295-303.

15. Roseboom TJ, van der Meulen JHP, Ravelli ACJ, Osmond C, Barker DJ, et al.
(2001) Effects of prenatal exposure to the Dutch famine on adult disease in later life: an overview. Molecular and Cellular Endocrinology 185(12): 93-98.

16. Trosko JE, Suzuki K (2009) Adult stem cells, the barker hypothesis, epigenetic events and low-level radiation effects. In: Nakashima M, Takamura N, et al. (Eds.), Radiation Health Risk Sciences, Springer Publisher, Tokyo, Japan, pp. 216-226.

17. Barker DJ (2004) The developmental origins of adult disease. J Am Coll Nutr 23(6 Suppl): 588s-595s.

18. Trosko JE (2009) Review paper: cancer stem cells and cancer non-stem cells: From adult stem cells or from re-programming of differentiated somatic cells. Vet Pathol 46(2): 176-193.

19. Markert CL (1968Z) Neoplasia: A disease of cell differentiation. Cancer Res 28(9): 1908-1914.

20. Potter VR (1978) Phenotypic diversity in experimental hepatomas: the concept of partially blocked ontogeny. Br J Cancer 38(1): 1-23.

21. Till JE (1982) Stem cells in differentiation and neoplasia. J Cell Physiol Suppl 1: 3-11.

22. Tai MH, Chang CC, Kiupel M, Webster JD, Olson LK, et al. (2005) Oct4 expression in adult stem cells: Evidence in support of the stem cell theory of carcinogenesis. Carcinogenesis 26(2): 495-502.

23. Bonnet D, Dick JE (1997 Human acute myeloid leukemia is organized as a hierarchy that originates from a primitive hematopoietic cell. Nature Med 3(7): 730-737.

24. Barker N, Ridgway RA, van Es JH, van de Wetering M, Begthel $\mathrm{H}$, et al. (2009) Crypt stem cells as the cells-of-origin of intestinal cancer. Nature 457(7229): 608-611.

25. Wang X, Kruithof-de Julio M, Economides KD, Walker D, Yu H, et al. (2009) A luminal epithelial stem cell that is a cell of origin for prostate cancer. Nature 461(7263): 495-500.

26. Sanchez A, Hannezo E, Larsimont JC, Liagre M, Youssef KK, et al. (2016) Defining the clonal dynamics leading to mouse skin tumor initiation. Nature 536(7616): 298-303.

27. Hanahan D, Weinberg RA (2000) The hallmarks of cancer. Cell 100(1): 57-70.

28. Hanahan D, Weinberg RA (2011) Hallmarks of cancer: the next generation. Cell 144(5): 646-674.

29. Trosko JE (2001) Commentary: is the concept of 'tumor promotion' a useful paradigm? Molecular Carcinogenesis 30(3): 131-137.

30. Leone A, Longo C, Trosko JE (2012) The chemopreventive role of dietary phytochemicals through gap junctional intercellular communication. Phytochem Rev 11(2-3): 285-307.

31. Marusyk A, Almendro V, Polyak K (2012) Intra-tumour heterogeneity: a looking glass for cancer? Nature Reviews/Cancer 12(5): 323-334.

32. Trosko JE (2009) Cancer prevention \& therapy of two types of gap junctional intercellular communication-deficient "cancer stem cells". Cancers 11(1): E87.

33. Trosko JE, Lenz HJ (2017) What roles do colon stem cells and gap junctions play in the left and right location of origin of colorectal cancers? J Cell Communication and Signaling 11(1): 79-87.

34. Saez JC, Berthoud VM, Moreno AP, Spray DC (1993) Gap junctions. Multiplicity of controls in differentiated and undifferentiated cells and possible functional implications. Adv Second Messenger Phosphoproteins Res 27: 163-198. 